\title{
THE PREVALENCE OF TUBERCULOSIS AT NECROPSY IN PROGRESSIVE MASSIVE FIBROSIS OF COALWORKERS
}

\author{
BY \\ D. RIVERS, W. R. L. JAMES, D. G. DAVIES, and S. THOMSON \\ From the Pneumoconiosis Research Unit of the Medical Research Council, Llandough Hospital, Cardiff, the Department \\ of Pathology and Bacteriology, Welsh National School of Medicine, Cardiff, and the Public Health Laboratory, Cardiff
}

(RECEIVED FOR PUBLICATION AUGUST 24, 1956)

The accumulation of dust particles in the lungs may produce harmful changes. At one time it was thought that serious damage to the lungs occurred only when the dust had a high content of free silica, but it is now accepted that coal, which contains only a small amount of free silica, can be associated with severe, and fatal, lung fibrosis (Gough, 1940).

It is well recognized that in classical silicosis, i.e., the disease associated with a dust rich in free silica, tuberculosis is a frequent complication. The common type of pneumoconiosis seen in coalworkers has two forms: (a) a simple type without significant fibrosis and (b) a complicated type with severe fibrosis which is believed to be caused in most cases by tuberculosis in a lung already loaded with dust (Fletcher and Gough, 1950, Cochrane, Miall, Clarke, Jarman, Jonathan, and Moore, 1956). Strong pathological evidence of tuberculosis is present in many cases at necropsy. Some years ago a search was made in our respective departments for tubercle bacilli using routine cultural techniques and guinea-pig inoculation tests; in a series of 75 cases of massive fibrosis $25(33 \%)$ were found positive (Fletcher, 1948). Other workers, whose results will be discussed later, did not make a systematic search for tubercle bacilli in all cases, and their conclusions were largely based on histological evidence. It therefore seemed possible that if a more vigorous search were made for tubercle bacilli, using improved methods of sampling the lung combined with the most efficient bacteriological methods, a larger proportion of positive cases might be found. The purpose of this paper is to report the findings of such an investigation.

Pathology of Coalworkers' Pneumoconiosis

All coal-miners have coal dust in their lungs, but many have no significant secondary pathological changes and suffer from no symptoms. At necropsy it is customary to recognize three main types of lesion.

Coal Nodules.-The lungs show foci of dust scattered almost uniformly throughout. Heppleston (1953) described the essential lesions as deposits of dust-laden macrophages enmeshed in a reticulin framework forming cuffs around the respiratory bronchioles. In some cases the foci contain and are surrounded by focal emphysema (Gough, 1940; Heppleston, 1953). Collagen fibres are scanty, and are mostly associated with older foci. The frequency and severity of focal emphysema increases with age.

Mixed Dust Nodules.-The lesion is a small fibrous nodule usually not more than $1.5 \mathrm{~cm}$. in diameter and heavily impregnated with coal dust. Any such nodule under $3 \mathrm{~cm}$. in diameter is included in this group. The nodule contains much collagen with fibres usually showing no well defined arrangement but which are sometimes disposed radially. The collagen often undergoes hyaline changes and there may be central ischaemic necrosis. The appearances of a nodule may be in some cases indistinguishable from an old healed tuberculoma containing coal dust. The lesions are termed "infective nodules" by those who consider that infection is a factor in their production. Others believe that the fibrosis is due to the silica in the dust and use the term "mixed dust nodules" (Di Biasi, 1954).

Progressive Massive Fibrosis (P.M.F.). - The lesion consists of a dense mass of collagen containing a large amount of coal dust. James (1954) accepted any lesion larger than $3 \mathrm{~cm}$. in diameter as a lesion of massive fibrosis, and we have followed this definition. In almost all cases in this series the lesions were considerably larger than $3 \mathrm{~cm}$. in 
diameter. The collagen fibres show no definite arrangement, and the edge of the lesion is usually irregular. Most of the bronchi and vessels within the mass are obliterated, and the vessels at the periphery often show advanced endarteritis (Wells, 1954). Some patches of the collagen may be hyaline and often, presumably because of avascular necrosis, a cavity appears in the mass. The lesions are usually large and bilateral, the common sites being the posterior parts of the upper lobes. Massive fibrotic lesions are associated with simple pneumoconiosis in the rest of the lung. The site of the lesions, the endarteritis, and cavitation are similar to those in tuberculous infection.

In experiments with guinea-pigs Zaidi, Harrison, King, and Mitchison (1955) found that the combined action of coal-mine dust and tubercle bacilli of low virulence produced massive pulmonary fibrosis, whereas the dust alone or the bacilli alone did not produce any fibrosis. Serial cultures of the lungs yielded growth of tubercle bacilli up to, but not beyond, 120 days. It may be that a similar process occurs in man and accounts for the failure to isolate tubercle bacilli from the majority of massive fibrotic lesions. The radiological appearances of early massive fibrosis and tuberculosis are often sufficiently similar to make them indistinguishable (Cochrane, 1954), and in the Rhondda Fach survey it was found that the prevalence of tuberculosis in miners was less than among non-miners unless massive fibrosis was included as a form of tuberculosis (Cochrane, Cox, and Jarman, 1952).

In the investigation reported here necropsy material from coalworkers was examined macroscopically, histologically, and bacteriologically for evidence of tuberculosis. Special efforts were made to release tubercle bacilli from the fibrotic masses before examination by animal inoculation test and culture.

\section{Choice of Material}

A large number of cases of suspected pneumoconiosis in coalworkers come to necropsy in Wales. The disease is compensatable, and deaths from it are referred to the coroner; necropsies are performed at the request of the coroner.

In this study 98 cases of massive fibrosis formed the first group and a further 20 cases forming a second group were added later. Each group was made up of consecutive cases on which necropsy was performed by two of the authors (W.R.L.J. and D.R.). Included for comparison were 18 cases of mixed nodular pneumoconiosis and 17 cases of simple pneumoconiosis. All these cases formed part of the routine post-mortem material during the years 1952-54 inclusive.

\section{Collection of Material}

At necropsy a swab was taken of the main bronchus immediately after the lungs had been removed from the thorax. This swab was taken in order to establish what might have been the result of an examination of a specimen of sputum had such a specimen been taken shortly before death. It was known from previous experience that tubercle bacilli are found in only very few cases of massive fibrosis during life, and it was thought desirable to establish whether or not this state of affairs persisted until death, i.e., whether the tubercle bacilli so often found in the fibrotic mass after death are entirely enclosed in tissue or are escaping in the sputum.

About $25 \mathrm{~g}$. of the fibrotic mass was excised from the lung and put in a sterile jar along with any hilar lymph nodes draining the area.

The cases of mixed nodular pneumoconiosis and simple pneumoconiosis were similarly examined by taking a large piece of lung containing nodules or dust foci and the associated hilar glands.

\section{Methods of Examination}

Swab of bronchus.-The swab was immersed in $2.5 \%$ oxalic acid for 45 minutes, and was then rubbed over the surface of Lowenstein-Jensen's medium (two tubes).

Fibrous Mass.-The mass and hilar gland were placed in a metal Waring blender together with $20 \mathrm{ml}$. of nutrient broth. After about two minutes at 15,000 r.p.m. the tissue was macerated, but sometimes it was necessary to treat it for a second period. At the end of this treatment the tissue, though macerated and appearing to be a uniform mush, could not be drawn up into a syringe as collagen fibres blocked the needle. Grinding the mush with a pestle and mortar, even along with sand, had no advantages as the collagen became knotted into a firm mass. As the liquor was not thought to be the best sample obtainable the mush was treated with $\mathrm{NaOH}$. Equal volumes $(2 \mathrm{ml}$.$) of 4 \% \mathrm{NaOH}$ and mush were mixed and held at $37^{\circ} \mathrm{C}$. for periods not exceeding 30 minutes. This produced considerable homogenization of the mush which was now diluted with $25 \mathrm{ml}$. of sterile distilled water and centrifuged at 3,000 r.p.m. for 30 minutes. The deposit was neutralized with $3 \% \mathrm{HCl}$, and cultures were made on Lowenstein-Jensen's medium and in Kirschner's medium (two tubes of each). At the same time a guinea-pig was inoculated. The whole of the deposit from $2 \mathrm{ml}$. of mush (representing approximately $1 \mathrm{~g}$. of tissue) was used for these tests, roughly equal volumes being cultured on Lowenstein-Jensen's or in Kirschner's medium or inoculated into a guinea-pig. A study of a number of homogenizing agents by a working party of the Public Health Laboratory Service (1952) on the laboratory diagnosis of tuberculosis showed $\mathrm{NaOH}$ to give the highest success rate for culture of tubercle bacilli from sputum. These findings have recently been confirmed by Gray, Clarke, and Johnstone (1954) for Mycobacterium tuberculosis H37Rv.

Nevertheless, as an additional check in an extra 20 cases of massive fibrosis the macerated tissue, undigested with alkali, was injected into guinea-pigs protected with gas gangrene and tetanus antitoxins. This was thought 
desirable in case $\mathrm{NaOH}$ in the presence of coal dust is harmful to tubercle bacilli. The material was not very satisfactory for injection, as little more than the liquor was drawn up into the syringe.

Histology.-In all cases two or more blocks of tissue from the lesions in each lung were taken for histological examination. Sections were stained by the haematoxylin and eosin method, and tuberculosis was diagnosed only if all the classical features were present.

\section{Results}

The cases were classified according to the type of pneumoconiosis and to the presence or absence of tuberculosis as judged by the naked-eye or histological changes. With a few exceptions the cases judged tuberculous showed both naked-eye evidence of the disease and the characteristic histological changes. The cases were classified before the results of the bacteriological examinations were known. The results are shown in Table 1,

TABLE 1

ISOLATION OF TUBERCLE BACILLI FROM CASES OF COALWORKERS' PNEUMOCONIOSIS

\begin{tabular}{|c|c|c|c|}
\hline \multirow{2}{*}{ Pathological Classification } & \multicolumn{3}{|c|}{ Bacteriological Result } \\
\hline & Positive & Negative & Total \\
\hline $\begin{array}{l}\text { Type } 1 \\
\text { Simple pneumoconiosis (without } \\
\text { tuberculosis) }\end{array}$ & 2 & 15 & 17 \\
\hline $\begin{array}{l}\text { Type } 2 \\
\text { Mixed nodular pneumoconiosis } \\
\text { Mixed nodules with tuberculosis }\end{array}$ & $\begin{array}{l}0 \\
2\end{array}$ & $\begin{array}{r}16 \\
0\end{array}$ & $\begin{array}{r}16 \\
2\end{array}$ \\
\hline $\begin{array}{l}\text { Type } 3 \\
\text { Progressive massive fibrosis } \\
\text { P.M.F. with tuberculosis } \\
\text { P.M.F. with doubtful tuberculosis }\end{array}$ & $\begin{array}{r}8 \\
31 \\
2\end{array}$ & $\begin{array}{r}72 \\
0 \\
5\end{array}$ & $\begin{array}{r}80 \\
31 \\
7\end{array}$ \\
\hline
\end{tabular}

and, since the results for the 20 cases of massive fibrosis examined by injecting untreated macerated lesions into guinea-pigs did not differ from those of the first series, the two groups are considered together.

There were in all 118 cases of massive fibrosis and tubercle bacilli were isolated from 41 (35\%). Thus refinement of techniques did not yield a greater proportion of successful isolations than had been obtained in earlier studies.

There was a very close agreement between the naked-eye and histological assessment and the bacteriological result; of 31 cases of massive fibrosis showing tuberculous tissue changes (naked-eye and microscopical), all were bacteriologically positive; of 80 cases of massive fibrosis with no obvious tuberculous changes, eight were positive; seven showed some appearances suspicious of tuberculosis and two were positive. All 16 cases of mixed nodular pneumoconiosis without tuberculous tissue changes were bacteriologically negative.
The finding of tubercle bacilli in two out of 17 cases of simple pneumoconiosis is surprising and may be the result of including the hilar glands in the material examined.

\section{Discussion}

Gooding (1946) reported post-mortem pathological evidence of tuberculosis in $26 \%$ of 230 cases certified as " silicosis" during life. In 1949, McVittie reported a similar finding ( $30 \%$ positive). Rogers (1946), on the other hand, reported the presence of tuberculosis in $75 \%$ of nearly 1,000 cases. It is difficult to account for the different findings of these workers but it is possible that it is caused by differences in the selection of the cases examined.

Similar divergent results are found in classical silicosis. Meiklejohn (1949 a and b) reviewed the literature and quoted that the proportion of cases complicated by tuberculosis varied from $46 \%$ to $75 \%$; in his own series of 750 necropsies on pottery workers he found $40 \%$ of the cases of silicosis to be positive (only $36 \%$ of the cases of advanced silicosis were positive).

Recently James (1954) reported a series of 454 cases of massive fibrosis with evidence of tuberculosis (usually histological but sometimes including demonstration of the bacillus) in $40 \%$, and also drew attention to the higher proportion of young men whose lesions were complicated by tuberculosis as compared with the older men. Of 17 cases under the age of 40,15 were positive $(88 \%)$, whereas in those aged 60 and over active tuberculosis was found in only 32 out of 112 cases $(29 \%)$. Our series is too small for analysis by age groups. This relationship of the prevalence of tuberculosis to age at necropsy may well be due in part also to the nature of selection by death, whereby the more fatal type of disease is predominant in the younger age groups. On account of the many factors which may influence the selection of post-mortem material one cannot draw any firm conclusions from the age distribution of tuberculosis at necropsy as to the association between such tuberculosis and the pneumoconioses during life. Nevertheless, Carpenter, Cochrane, Jarman, and Miall (1956) note the decline of the prevalence of positive sputum with increasing age in cases of massive fibrosis in the Rhondda Fach.

Tubercle bacilli are found in the sputum of only a small proportion of cases of massive fibrosis during life. In the Rhondda Fach Survey Cochrane et al. (1952) found only $1 \cdot 1 \%$ positive by laryngeal swabbing; in contrast $2.29 \%$ of apparently healthy women between the ages of 20 and 25 were positive. In cases of massive fibrosis studied as in-patients of the Pneumoconiosis Research Unit 7.7\% showed tubercle bacilli in sputum examined by culture and 
guinea-pig inoculation (Kilpatrick, Heppleston, and Fletcher 1954). Our results show that cultures taken from the bronchus before the lung had been incised at necropsy yielded $33(28 \%)$ positive (see Table 2), and it would seem probable that if a

TABLE 2

ISOLATION OF TUBERCLE BACILLI FROM 41 CASES OF PROGRESSIVE MASSIVE FIBROSIS

\begin{tabular}{|c|c|c|c|c|}
\hline \multirow[b]{2}{*}{ Group } & \multirow{2}{*}{$\begin{array}{c}\text { Total } \\
\text { Positive }\end{array}$} & \multicolumn{3}{|c|}{ No. Positive by Method of Examination } \\
\hline & & $\begin{array}{l}\text { Culture of } \\
\text { Swab of } \\
\text { Bronchus }\end{array}$ & $\begin{array}{l}\text { Culture of } \\
\text { Lung or } \\
\text { Gland }\end{array}$ & $\begin{array}{l}\text { Guinea-pig } \\
\text { Inoculation } \\
\text { of Lung or } \\
\text { Gland }\end{array}$ \\
\hline P.M.F. & 8 & 2 & 7 & 8 \\
\hline $\begin{array}{c}\text { P.M.F. with } \\
\text { o b } \text { i i o u s } \\
\text { tuberculosis }\end{array}$ & 31 & 29 & 30 & 31 \\
\hline $\begin{array}{l}\text { P.M.F. with } \\
\text { suspicion of } \\
\text { tuberculosis }\end{array}$ & 2 & 2 & 2 & 2 \\
\hline Totals .. & 41 & 33 & 39 & 41 \\
\hline
\end{tabular}

specimen of sputum had been examined shortly before death it also would have yielded tubercle bacilli. This is supported by the results in the hospital population which indicate an association of "illness" with increased prevalence of tuberculosis. The prevalence of tuberculosis in patients admitted to hospital lay between that found in patients living at home and that found at necropsy.

Table 3 has been added to show that there are a large number of cases of massive fibrosis with

TABLE 3

CAVITATION AND/OR NECROSIS IN CASES OF

\begin{tabular}{l|c|c}
\hline $\begin{array}{c}\text { Isolation of } \\
\text { Tubercle Bacilli }\end{array}$ & $\begin{array}{c}\text { Cavitation } \\
\text { and/or Necrosis }\end{array}$ & $\begin{array}{c}\text { No Cavitation } \\
\text { and/or Necrosis }\end{array}$ \\
\hline $\begin{array}{l}\text { Positive } \\
\text { Negative }\end{array}$ & $36(40 \%)$ & $5(17 \%)$ \\
\hline
\end{tabular}

cavities which do not yield tubercle bacilli. A similar observation has been made in a hospital population during life (Kilpatrick et al., 1954).

There is undoubtedly a high prevalence of tuberculosis in the cases of massive fibrosis which come to post-mortem examination, and it is not clear if this is a breakdown of an old tuberculous infection which was necessary to the formation of the lesion, or a recent infection by tubercle bacilli into a previously non-tuberculous massive fibrous lesion.

Finally, our results show that more careful and detailed search for tubercle bacilli in the massive lesions did not yield a higher proportion of positive cases than had been previously reported.

\section{Summary}

One hundred and fifty three cases of coalworkers ${ }^{\circ}$ pneumoconiosis were examined at necropsy for the presence of tubercle bacilli both by culture and by animal inoculation. The series contained 118 cases of progressive massive fibrosis which were the special object of this study. Tubercle bacilli were isolated from 41 cases $(35 \%)$ of massive fibrosis, and in $31(28 \%)$ of these naked-eye or histological evidence of tuberculosis was recognized pathologically. The pathological observations, therefore, correlated well with the bacteriological results. There is a marked difference between the prevalence of tuberculous infection found in a post-mortem series and that found during life in cases of progressive massive fibrosis. During life the observed prevalence is only $1.1 \%$. We found tubercle bacilli in the bronchi at necropsy in $28 \%$. Thus open tuberculosis is, in most cases, a late complication of massive fibrosis. Whether or not tuberculous infection occurs early or late cannot be deduced from this study.

We are grateful to Professor J. Gough for permission to use his material and for his advice and criticism. We are also grateful to Dr. J. C. Gilson and members of the Pneumoconiosis Research Unit for their advice and criticism.

\section{REFERENCES}

Carpenter, R. G., Cochrane, A. L., Jarman, T. F., and Miall, W. F (1956). Tubercle, 37, 225.

Cochrane, A. L. (1954). Brit. J. Tuberc., 48, 274.

Cochrane, A. G., and Jarman T. F. (1952). Brit. med. J., 2, 843.

Miall, W. E., Clarke, W. G., Jarman, T. F., Jonathan, G., and Miall, W. E., Clarke, W. G., Jarman,

Di Biasi, W. (1954). In Die Siaublungenerkrankungen, vol. 2, ed. Jötten, K. W., Klosterkötter, W., and Pfefferkorn, G. (Proceedings of the second international conference on dust diseases of the lung, Münster, 1953), p. 16, Steinkopff, Darmstadt.

Fletcher, C. M. (1948). Brit. med. J., 1, 1065

-, and Gough, J. (1950). Brit. med. Bull., 7, 42.

Gooding, C. G. (1946). Lancet, 2, 891.

Gough, J. (1940). J. Path. Bact., 51, 277.

Gray, D. F., Clarke, B. L., and Johnstone, W. E. (1954). Amer. Rev. Tuberc, 69, 991 .

Heppleston, A. G. (1953). J. Path. Bact., 66, 235.

James, W R L (1954), Brit.J. Tuberc, 48, 89.

Kilpatrick, G. S., Heppleston, A. G., and Fletcher, C. M. (1954)

Thorax, 9, 260.

Meikleiohn. A. (1949a). British Journal of Industrial Medicine, 6, 230

Meiklejohn, A. (1949a). Britsh

Public Health Laboratory Service (1952). Monthly Bull. Minist. Hlth (Lond.), 11, 187

Rogers, E. (1946). Lancet, 1, 462.

Wells, A. L. (1954). J. Path. Bact., 68, 573.

Zaidi, S. H., Harrison, C. V., King, E. J., and Mitchison, D.A. (1955) Brit.J. exp. Path., 36, 553 . 